\title{
A INTERFACE DA PRESERVAÇÃO DO MEIO AMBIENTE POR MEIO DA SUSTENTABILIDADE COMO PRINCÍPIO DE DIREITO AGRÁRIO: A HERMENÊUTICA QUE TRANSCENDE AS LINHAS IMPOSTAS EM BUSCA DE UM NOVO PARADIGMA
}

THE INTERACTION BETWEEN ENVIRONMENTAL PRESERVATION THROUOUT SUSTAINABILITY AS AN AGRARIAN LAW PRINCIPLE: HERMENEUTICS TRANSCENDING BORDERS IN ORDER TO OBTAIN A NEW PARADIGM

\author{
${ }^{1}$ Luciana Ramos Jordão \\ ${ }^{2}$ Caroline Vargas Barbosa
}

\section{RESUMO}

O presente trabalho discute a problematização da preservação do meio ambiente como princípio hermenêutico do Direito Agrário. Busca a compreensão da correlação entre ambos segmentos do Direito a partir de uma refundação da Sustentabilidade como preceito maior ao desenvolvimento agrário e preservação ambiental. Por meio do método dedutivo, trabalha o fato de não mais se poder enxergar o meio ambiente (e o estudo do Direito) de forma segmentada, incorrendo no risco de danos ambientais e agrários de alta complexidade. Assim, é necessário a consciência de seu elo, como uma questão de fundamentalidade e materialidade de direitos hoje meramente formais.

Palavras-chave: Direito agrário, Direito ambiental, Agroecologia, Sustentabilidade

\begin{abstract}
This paper discusses environmental preservation as a principle of Agrarian Law and hermeneutics. It aims to comprehend connection between both concepts from refounding Agroecology and Sustainability as a major precept in order to obtain agrarian development and environmental preservation. By using the deductive method, it analyses the fact that environment (and studying Law) cannot be seen in separate ways, otherwise, it would risk having high complexity environmental and agrarian damage. Therefore, consciousness of how dependent human is from environment as an issue of fundamentality and materiality of mere formal rights nowadays.
\end{abstract}

Keywords: Agrarian law, Environmental law, Environmental preservation, Agroecology, Sustainability

\footnotetext{
${ }^{1}$ Mestre em Direito Agrário pela Universidade Federal de Goiás - UFG, Goiás (Brasil). Professora da Universidade

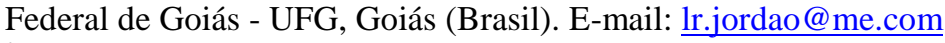

${ }^{2}$ Mestre em Direito Agrário pela Universidade Federal de Goiás - UFG, Goiás (Brasil). Professora da Faculdade Cambury de Goiânia, Goiás (Brasil). E-mail: advcarol.vargas@gmail.com
} 


\section{INTRODUÇÃO}

Considerando o crescente destaque conferido às questões ambientais, e, no caso das ciências jurídicas, do Direito Ambiental, é mister comentar acerca da influência dos conceitos oriundos desta disciplina em outras áreas do Direito. Em razão da estreita ligação existente o Direito Agrário e o Ambiental, o artigo se propõe a discutir como princípio agrário da preservação do meio ambiente e da sustentabilidade a fim de analisar se as questões que permeiam os conflitos existentes nos espaços rurais podem ser resolvidos apenas com institutos tipicamente ambientais.

A variável ambiental compõe um dos requisitos para aferir o cumprimento da função social, mas não é o único. Por esta razão, agraristas clássicos defendiam escolhas que servissem para aumentar a produtividade em detrimento daquelas que preservassem o ambiente. Assim, poder-se-ia, em primeira análise, entender que o Direito Agrário não poderia ser associado ao Direito Ambiental em virtude de aquele ter como objetivo a relação de produção existente entre o ser humano e a terra. Contudo, após o advento da Constituição de 1988, tornou-se difícil ignorar o princípio da preservação do ambiente enquanto norma de Direito Agrário.

Para tanto, é necessário refletir se o Direito Ambiental e o Direito Agrário são, de fato, ramos antagônicos. A princípio, entende-se que devem ser analisadas em conjunto as questões agrárias e ambientais, a fim de estabelecer relação equilibrada e voltada à obtenção do desenvolvimento sustentável, mas apenas análise detida será capaz de começar a responder tais questionamentos.

Este artigo discute os impactos ambientais causados pela atividade agrícola, trazendo à discussão dados provenientes de estudos feitos por profissionais das Ciências Agronômicas. Em seguida, destaca-se o conteúdo do princípio da preservação do meio ambiente e sustentabilidade. Por fim, coloca-se panorama a respeito da relação entre o Direito Agrário e o Direito Ambiental.

Para alcançar o objetivo principal do trabalho, debate-se o fato de não mais se poder enxergar o meio ambiente (e o estudo do Direito) de forma segmentada, incorrendo no risco de danos ambientais e agrários de alta complexidade. Em um primeiro momento, são demonstrados os riscos advindos da produção em larga escala trazida pelo capitalismo. Posteriormente, trabalha-se a ideia de preservação ambiental como princípio do Direito Agrário eis que este precisa daquele para sua manutenção e desenvolvimento. 
$\mathrm{O}$ artigo discute a necessidade da consciência do elo entre o ser humano e o ambiente, como uma questão de fundamentalidade e materialidade de direitos, hoje, meramente formais. Por fim, destaca-se a agroecologia e a sustentabilidade como paradigmas hermenêuticos que dão substancia a preservação do meio ambiente e da pluralidade de indivíduos, culturas e necessidades em prol do (re)encontro do homem com o meio ambiente e o resguardo ambiental às futuras gerações.

Nunca é suficiente salientar que a função do presente trabalho não é apresentar uma verdade incontestável, e, menos ainda, colocar fim à discussão. O que se espera aqui é contribuir para o desenvolvimento de um Direito mais justo, que atenda às necessidades do ser humano e respeite suas limitações.

\section{DOS IMPACTOS AMBIENTAIS CAUSADOS PELA PRODUÇÃO AGRÍCOLA}

A monocultura apresenta-se como sistema bastante simples e economicamente lucrativo, uma vez que possibilitou a simplificação da organização do trabalho, a desnecessidade de mão-de-obra qualificada e de coordenação cuidadosa das diversas atividades desempenhadas na propriedade rural. A floresta natural, vista como sistema caótico e economicamente inútil ao ser humano, deveria dar lugar a sistemas passíveis de serem administrados de modo a produzir o que fosse mais necessário ao homem de modo uniforme e objetivo. A diversidade daria espaço a espécies isoladas de mesma faixa etária protegidas de pragas por meio da utilização de insumos externos (EHLERS, 1999; GLIESSMAN, 2005).

Desde a Segunda Revolução Agrícola temos o uso de fertilizantes químicos e a descoberta do aço, usado para confeccionar arados e colhedeiras inicialmente puxados por animais, posteriormente substituídos por tratores têm sido utilizados para o aumento produtivo. Além disso, os estudos desenvolvidos por Johann Gregor Mendel (1822-1884) sobre a genética e a hereditariedade, facilitaram a prática de seleção de características desejáveis em vegetais, dando início à produção de variedades geneticamente melhoradas e de híbridos (EHLERS, 1999). Por fim, as Guerras Mundiais deixaram como herança armas químicas que se converteram em inseticidas, pesticidas e agrotóxicos, e prometiam exterminar de vez as pragas que assombravam os produtores (GLIESSMAN, 2005).

A Revolução Verde, ocorrida no início dos anos 70, marcou o início de um novo modelo de cultivo, e foi resultado da substituição dos moldes de produção tradicionais por 
outro baseado na utilização de variedades vegetais geneticamente melhoradas, muito exigentes em fertilizantes químicos de alta solubilidade, além de agrotóxicos com maior poder biocida, de irrigação e motomecanização. O pacote tecnológico viabilizou a adoção em larga escala de sistemas monoculturais na Europa e nos Estados Unidos e afastou ainda mais a agricultura da pecuária. Como resultado das práticas que compõem o padrão tecnológico da Revolução Verde houve relevante incremento na produção de gêneros alimentícios e chegouse a propalar o fim do problema da fome no planeta. As descobertas agronômicas se espalharam por vários países, sobretudo países de Terceiro Mundo em razão da fragilidade da legislação ambiental e de fiscalização pouco eficiente, apoiadas nos incentivos fornecidos pelos governos, pelo Banco Mundial, pela Organização das Nações unidas para a Agricultura e a Alimentação, entre outras (EHLERS, 1999).

$\mathrm{O}$ uso de fertilizantes artificiais perturba o equilíbrio e a vida existente no solo, uma vez que faz aumentar a taxa de decomposição de matérias orgânicas, conduz à degradação de sua estrutura, à maior vulnerabilidade à seca e diminui a eficácia produtiva (WALTERSBAYER, 1999; GLIESSMAN, 2005). O empobrecimento do solo implica a necessidade de aplicação de maiores quantidades de fertilizantes químicos, o que resulta no desenvolvimento de resistência a agrotóxicos por parte das pragas, conseqüentemente, também ocorre aumento de seu uso nas plantações. Desta feita, os custos de produção tornam-se mais elevados e há declínio na produção de alimentos em razão da degradação dos recursos naturais (EHLERS, 1999).

Os pesticidas atingem o ar, o solo, a água e produzem efeitos sobre os seres vivos de modo geral, causando danos particularmente sensíveis aos organismos aquáticos, mais vulneráveis a seus efeitos negativos. Por não se decomporem facilmente, são absorvidos pela cadeia alimentar, causando reflexos em insetos, plantas e animais, e chegando ao ser humano nos alimentos consumidos (WALTERS-BAYER, 1999).

A redução da variabilidade genética, também conhecida como erosão genética, causada por estes processos de transformação da prática e sistemas agropecuários tradicionais, provoca a perda de conhecimentos sobre espécies nativas e seus possíveis usos pela população local. A erosão genética se dá, em grande medida como resposta às exigências do mercado. O agricultor pretere as variedades já adaptadas ao ambiente local em favor de outras que sejam economicamente mais rentáveis (MACHADO, 2008). 
O pacote da Revolução Verde foi criado para substituir a diversidade genética em dois níveis. Primeiro, as safras mistas e a rotação de diversas culturas como o trigo, o milho, o painço, legumes e sementes oleaginosas foram substituídas por monoculturas de trigo e arroz. Em segundo lugar, as variedades de trigo e arroz que foram introduzidas e reproduzidas em larga escala como monoculturas têm uma base genética limitadíssima, em comparação com a grande variedade genética da população tradicional do trigo e do arroz (SHIVA, 2003, p. 66).

As modernas técnicas de melhoramento genético e desenvolvimento de espécies resistentes a pragas e terminaram por dilapidar a diversidade biológica, promovendo uniformização dos organismos altamente dependentes de insumos externos (MACHADO, 2008). O plantio monocultor permite o alastramento de pragas sem imposição de quaisquer empecilhos. Se uma planta é atacada por uma erva daninha, doença ou inseto, todas serão, e nenhuma terá sucesso em sobreviver ao ataque, uma vez que todas trazem mesma carga genética (SHIVA, 2003).

Diante dos problemas relacionados à perda da diversidade biológica, empobrecimento do solo, desertificação, erosão, contaminação do meio ambiente e dos seres vivos por agrotóxicos, alterações climáticas e exploração predatória dos recursos naturais, alto preço dos insumos externos, estudiosos ligados às ciências agronômicas passaram a concentrar esforços em discutir um modelo de agricultura que permitisse a preservação dos recursos ora disponíveis sem ignorar os avanços tecnológicos já incorporados à vida do agricultor. Fala-se, pois, em agricultura sustentável.

Miguel Altieri (2004, p. 65), engenheiro-agrônomo, esclarece que a “[...] agricultura sustentável geralmente refere-se a um modo de fazer agricultura que busca assegurar produtividades sustentadas a longo prazo, através do uso de práticas de manejo ecologicamente seguras", para isso é necessário direcionar pesquisas para que apontem não apenas o caminho da maior produtividade, mas que considerem a estabilidade e a manutenção dos sistemas ecológicos afetados pela atividade agrícola.

É evidente que o destino da agricultura e seu encontro com o ideal da sustentabilidade não é assunto pacífico entre os estudiosos. Vandana Shiva (2003, p. 77), por exemplo, acredita na abolição do uso de fertilizantes artificiais. Segundo a autora, "A agricultura sustentável baseia-se na reciclagem dos nutrientes do solo. Isso implica devolver ao solo parte dos nutrientes que vêm dele, seja diretamente como fertilizante orgânico, seja indiretamente, por meio do esterco dos animais criados nas fazendas".

A agricultura sustentável pauta-se na manutenção dos recursos naturais, no mínimo impacto ambiental, no menor uso de insumos artificiais, na consecução de melhores 
resultados para os produtores rurais, no atendimento a demanda por alimentos, proporcionando ainda o bem-estar social ao produtor, à sua família e à comunidade.

Para que se alcance a sustentabilidade na produção agrícola é necessário assegurar condições adequadas para o desenvolvimento das plantas por meio do manejo de matéria orgânica, utilizando fertilizantes externos apenas de modo complementar, além de adotar a tecnologia mais adequada a cada tipo de área, considerando não somente o produto a ser cultivado, mas o clima, a disponibilidade de água, as condições do solo, e as carências da população local (VOGTMANN, WAGNER, 1987).

\section{DA PRESERVAÇÃO DO AMBIENTE COMO PRINCÍPIO DE DIREITO AGRÁRIO}

Conforme ensina Luis Roberto Barroso(2009), os princípios expressam valores ou fins a serem alcançados, indicam estados ideais que podem remeter à condutas diversas e dependem, caso entrem em conflito com outros princípios, da ponderação.

Neste mister, é de se concluir pelo enquadramento da preservação do ambiente como princípio de Direito Agrário, uma vez que a interpretação das regras que o regem passa necessariamente pela observância de condutas que menos prejudiquem o ambiente e permitam que a produção agrícola possa ser desenvolvida de modo sustentado. Ademais, nem sempre a preservação do meio convive de modo pacífico com a produção.

No que tange à interpretação, é válido ressaltar que princípios são normas, ou mandamentos de otimização, devendo ser aplicados em máximo grau possível de acordo com as possibilidades jurídicas e fáticas. E, só é dado dizer se um princípio foi ou não aplicado em grau máximo quando ele se coloca em choque com outro princípio (ALEXY, 2011).

\footnotetext{
As colisões entre princípios devem ser solucionadas de forma completamente diversa. Se dois princípios colidem - o que ocorre, por exemplo, quando algo é proibido de acordo com um princípio e de acordo com outro, permitido -, um dos princípios terá que ceder. Isso não significa, contudo, nem que o princípio cedente deva ser declarado inválido, nem que nele deverá ser introduzida uma cláusula de exceção. Na verdade, o que ocorre é que um dos princípios tem precedência em face do outro sob determinadas condições. Sob outras condições a questão da precedência pode ser resolvida de forma oposta (ALEXY, 2011, p. 93).
}

Embora seja também requisito para verificação do cumprimento da função social, a preservação do meio ambiente deve ser entendida como princípio de Direito Agrário, já que por vezes está em desacordo com o mandamento que pugna pela necessidade de produção. Benedito Ferreira Marques (2005) cita o combate à monocultura, à exploração predatória da 
terra, e a conservação dos recursos naturais como princípios norteadores do Direito Agrário. No entanto, entende-se que estes aspectos integram as condições para satisfação do princípio da preservação do meio ambiente.

Não é conveniente realizar análise pormenorizada de cada aspecto, uma vez que devem ser compreendidos de modo sistêmico e indissociável. O meio ambiente em si é um sistema. O desequilíbrio de um aspecto traz instabilidade a todos os outros (MILARÉ, 2009; BECK, 2002). Portanto, as variáveis devem ser tomadas de forma a considerar sua influência no desenvolvimento das atividades agrárias como um todo.

Para tanto, é importante refletir com mais vagar acerca do conteúdo deste princípio, relacionando-o aos conceitos de biodiversidade e de desenvolvimento sustentável, que muito interessam ao Direito Agrário. Sobretudo porque, como princípio de Direito Agrário, a preservação do ambiente possui força normativa (HESSE, 1991) e tem o condão de orientar não apenas o exercício das atividades agrárias pelo homem do campo, pelo empresário rural, como também pelos entes públicos e privados que de algum modo participam da produção.

Inicialmente, é relevante considerar que a proteção ou conservação da natureza e o bem-estar do ser humano são os fundamentos do princípio da preservação do ambiente.

De fato, o grande desafio que ora se apresenta remete à dificuldade de conciliar o desenvolvimento econômico e a preservação ambiental. Julgava-se que a degradação do meio ambiente era consequência natural do desenvolvimento. Todavia, contemporaneamente, falase da necessidade de encontrar alternativas que permitam que as futuras gerações também tenham acesso aos recursos naturais disponíveis às gerações presentes, por isso é crescente a discussão acerca do uso sustentável dos recursos.

Diante da evidente possibilidade de esgotamento dos recursos naturais, a sustentabilidade se apresenta como alternativa a ser obrigatoriamente seguida a fim de propiciar a existência humana no planeta e dar continuidade ao desenvolvimento tecnológico que proporciona melhores condições de vida às pessoas.

Cabe destacar que o desenvolvimento sustentável é um processo, e não se confunde com sustentabilidade, que está associada à durabilidade dos recursos. "[...] a sustentabilidade dos recursos naturais não é absoluta, é relativa: depende de sua disponibilidade real e do quanto e do como eles são explorados, transformados e utilizados, até serem reduzidos à condição última de rejeitos finais" (MILARÉ, 2009, p. 72). 


\begin{abstract}
Constata-se que os recursos ambientais não são inesgotáveis, tornando-se inadmissível que as atividades econômicas desenvolvam-se alheias a esse fato. Busca-se com isso a coexistência harmônica entre economia e meio ambiente. Permite-se o desenvolvimento, mas de forma sustentável, planejada para que os recursos hoje existentes não se esgotem ou tornem-se inócuos (FIORILLO, 2009, p. 27).
\end{abstract}

A primeira referência ao conceito de desenvolvimento sustentável no Direito brasileiro encontra-se na Lei 6.803 , de 1980, que dispõe sobre as diretrizes básicas para o zoneamento industrial nas áreas críticas de poluição ${ }^{1}$. Em 1981, a Lei 6.938 coloca como objetivo da Política Nacional do Meio Ambiente (PNMA) a compatibilização do desenvolvimento econômico-social com a preservação da qualidade do meio ambiente e do equilíbrio ecológico.

Esta determinação tenta alterar a mentalidade puramente econômica, para que os padrões de produção sejam pautados no reaproveitamento, redução e reciclagem de materiais. Assim, toda decisão, seja política, seja econômica ou social, deve ter como foco o desenvolvimento sustentável caracterizado sobretudo pelo uso controlado dos recursos disponíveis, impedindo que se esgotem.

Até mesmo a livre iniciativa, fundamento da República, passou a ser vista sob novo prisma, isto é de modo mais restrito, na medida em que não há liberdade absoluta quando se trata do meio ambiente ecologicamente equilibrado. "Busca-se, na verdade, a coexistência de ambos sem que a ordem econômica inviabilize um meio ambiente ecologicamente equilibrado e sem que este obste o desenvolvimento econômico" (FIORILLO, 2009, p. 36).

É mister ponderar que a preservação do meio ambiente não se impõe de modo absoluto. Ora, o direito é produzido por homens e voltado à consecução de seus objetivos primordiais. O objetivo econômico é um deles. Se a defesa plena do meio ambiente constitui entrave ao desenvolvimento econômico, é bastante provável que haverá de se curvar às necessidades econômicas. Evidentemente, isso não significa o abandono do princípio, mas sua relativização, na medida em que, para que se alcance o objetivo econômico, deve-se traçar o caminho que menos agrida o meio ambiente. E tal caminho só poderá ser trilhado se tais danos não forem irreversíveis.

A preservação dos recursos naturais não deve significar entrave absoluto ao desenvolvimento. Ao contrário, o objetivo é garantir a vida humana digna. Neste sentido ensina Celso Antônio Pacheco Fiorillo (2009, p. 36): 


\begin{abstract}
Devemos lembrar que a idéia principal é assegurar existência digna, através de uma vida com qualidade. Com isso, o princípio não objetiva impedir o desenvolvimento econômico. Sabemos que a atividade econômica, na maioria das vezes, representa alguma degradação ambiental. Todavia, o que se procura é minimizá-la, pois pensar de forma contrária significaria dizer que nenhuma indústria que venha a deteriorar o meio ambiente poderá ser instalada, e essa não é a concepção do texto. O correto é que as atividades sejam desenvolvidas lançando-se mão dos instrumentos existentes adequados para a menor degradação possível.
\end{abstract}

No que atine as atividades agrárias, já se verifica que a agricultura monocultora, com uso irrestrito de fertilizantes artificiais, agrotóxicos, irrigação, e sementes de alto rendimento causam danos ambientais e sociais bastante sensíveis, contrariando os princípios agrários e ambientais.

O princípio da preservação do ambiente, a fim de refletir o binômio preservação da natureza e qualidade de vida, reputa-se atendido quando, no desempenho da atividade, o produtor se preocupa com a manutenção da diversidade biológica, do potencial produtivo do solo, das condições climáticas, e da disponibilidade de recursos naturais.

Segundo se definiu durante a Convenção sobre Diversidade Biológica, considerada um dos mais importantes instrumentos internacionais relacionados ao meio-ambiente, "Diversidade biológica significa a variabilidade de organismos vivos de todas as origens, compreendendo, dentre outros, os ecossistemas terrestres, marinhos e outros ecossistemas aquáticos e os complexos ecológicos de que fazem parte; compreendendo ainda a diversidade dentro de espécies, entre espécies e de ecossistemas" (CONFERÊNCIA DAS NAÇÕES UNIDAS SOBRE MEIO AMBIENTE E DESENVOLVIMENTO, 1992, art. $2^{\circ}$ ).

É evidente que estas conseqüências do uso inadequado da terra, voltado exclusivamente para o incremento da produtividade a curto prazo, em nada beneficiam a população, prejudicando especialmente o produtor familiar, incapaz de competir com as grandes empresas rurais. Produzir é importante, mas é igualmente indispensável que se continue produzindo, e isso só será possível mediante o fiel cumprimento do princípio da preservação do ambiente quando do desempenho de atividades agrárias.

\footnotetext{
${ }^{1}$ Art. $1^{\circ}$. Nas áreas críticas de poluição a que se refere o art. $4^{\text {o }}$ do Decreto-lei $\mathrm{n}^{\mathrm{o}} 1.413$, de 14 de agosto de 1975 , as zonas destinadas à instalação de indústrias serão definidas em esquema de zoneamento urbano, aprovado por lei, que compatibilize as atividades industriais com a proteção ambiental.
} 


\section{A (RE)TOMADA DE CONSCIÊNCIA: O MEIO AMBIENTE E O HOMEM E A FUNDAMENTALIDADE DE DIREITOS}

Nesse diapasão, torna-se válida e necessária a reflexão acerca dos meios e das tecnologias utilizados para a exploração do meio ambiente e de suas consequências para o presente e o futuro. Essa concepção deriva do reconhecimento da existência de riscos ambientais nas atividades humanas os quais não podem ser negligenciados. Contemporaneamente, vive-se em uma sociedade de risco, na qual o desenvolvimento se encontra, sem controles, alicerçado na crença da infalibilidade da ciência e das tecnologia. Deste modelo, contudo, decorrem riscos futuros incalculáveis nos âmbitos político, econômico, social e ambiental, riscos que podem, inclusive, culminar na dizimação de diversas espécies e culturas. Tal modelo não seria algo exclusivo das grandes potências, pois as dimensões dos riscos ultrapassam barreiras geográficas ou políticas (BECK, 1999).

Nesse contexto, o controle ambiental das atividades humanas se faz necessário e urgente uma vez que perpassa o uso equilibrado e racional dos recursos ambientais disponíveis, por meio de normas de aplicação imediata que limitem sua utilização, e não princípios de utópico alcance. (LEITE, AYALA, 2004). Em um contexto em que a transição industrial prol capitalismo não é uma escolha, e sim, uma consequência natural da evolução societária e um caminho aparentemente sem via reversa, o uso racional dos recursos disponíveis deve ser analisado sob a perspectiva do efeito bumerangue (BECK, 1999), segundo o qual os males praticados ao meio ambiente, mesmo quando não perceptíveis no momento no qual são praticados, trarão resultados às futuras gerações, podendo cercear seu direito a um meio ambiente sadio e equilibrado e até à sua própria existência.

Trata-se da possibilidade de volta dos efeitos de atos praticados por outros, em épocas diversas, com o potencial de ocasionar a destruição em massa ou diminuição significativa da qualidade de vida no decorrer dos anos. Por suas possíveis graves consequências, tais interesses e necessidades, mesmo futuras, devem ser tuteladas no presente pelo Estado. Isto porque, a tradicional perspectiva antropocêntrica dos direitos, a qual separa de forma inequívoca o homem da natureza na qual está inserido, passa a dar lugar a um novo enfoque que resgata a dimensão humana compreendida na natureza e vice-versa.

Protegendo-se o meio ambiente, garante-se, na verdade, toda a condição de vida existente. Trata-se da construção de condições mínimas para a perpetuação da vida em nível satisfatório. Sendo a concepção de direitos humanos fundamentada na constituição básica e material de vida, não há como dissociar da globalização e da sociedade capitalista 
contemporânea a sua proteção. Desse modo, a economia, a política, a cultura e os direitos dos cidadãos devem ser aliados ao meio ambiente sustentável, fornecendo eficácia e garantia dos direitos humanos à todos (SOUZA, 1995).

A violação de direitos ambientais, em última instância, configura uma violação a direitos humanos de sujeitos múltiplos e difusos. Atinge as gerações futuras, inclusive no que tange o uso de direitos econômicos, sociais e culturais. Isso porque, é imensurável o alcance dos resultados futuros das degradações ambientais presentes. Por isso, os danos causados tanto quanto os sujeitos de direito violado são indetermináveis (CARVALHO, 2008). Desse modo, a sociedade de risco e o Estado de Bem-estar alinham-se em dois momentos. No primeiro, na autoidentidade da própria sociedade de risco em razão das más escolhas industriais. No segundo, na sobreposição da distribuição de males e bens à toda a sociedade (BECK, 1999).

São assim, três as mudanças necessárias e urgentes à sociedade de risco contemporânea. A primeira é a mudança na relação da sociedade industrial moderna com os recursos da natureza e da cultura, respeitando-os. A segunda é a mudança da relação cos problemas produzidos junto a sociedade. A terceiro é a mudança da perspectiva que prevê o processo de individualização de grupos conforme a concepção de progresso (BECK, 1999). A definição de pós-modernidade deve ser cristalizada neste contexto, como o desenvolvimento social para uma consciência ambiental que modifique a ordem jurídica, social e econômica existente (GIDDENS, 1991). Consolida-se, desta feita, uma nova relação humana com os meios de produção, mudando o pensamento capitalista em favor da proteção e da conservação da natureza, para o desenvolvimento sustentável e paritário de toda a sociedade, deixando uma herança benéfica às futuras gerações (LÖWY, 2005).

Em razão das possíveis consequências das atividades humanas desenvolvidas no contexto da sociedade de risco, normas nacionais e internacionais consolidaram a jurisdicionalização da proteção dos interesses e necessidades das atuais e futuras gerações, integrando-as com a obrigação de proteção, sustentabilidade e melhoramento do meio ambiente natural existente.

Até meados do século XX, o direito internacional clássico desconhecia as obrigações erga omnes, estando pautado apenas nas relações interestatais, mormente nas de caráter exclusivamente bilateral. Como forma de resguardar o interesse comum da espécie humana, tal obrigação passou a ser registrada, dentre outros, na Declaração de Estocolmo sobre o Meio Ambiente Humano de 1972, em seu artigo primeiro, firmou-se que o homem é portador solene da obrigação de proteger e melhorar o meio ambiente, para as gerações presentes e 
futuras. E ainda, na Declaração sobre a Responsabilidade das Presentes Gerações em Torno das Futuras Gerações que a garantia da manutenção e perpetuação da humanidade, com o devido respeito à dignidade da pessoa humana, depende da manutenção da natureza, e ainda, que "[...] as gerações presentes têm a responsabilidade de legar às gerações futuras uma terra que não esteja irreversivelmente danificada pela atividade humana (UNESCO, 1997)."

Seguindo as orientações internacionais, a Constituição Federal Brasileira de 1988 estabeleceu, em norma programática, no seu Capítulo VI, art. 225, caput, o direito ao meio ambiente adequado e equilibrado para o uso comum da sociedade. Nesse diapasão, a proteção ao meio ambiente natural e a garantia de um meio ambiente ecologicamente equilibrado passam a ser tratados como direitos constitucionais e, inclusive, interpretados como dimensões do próprio princípio da dignidade da pessoa humana. Isto porque passam a ser vistas, ao mesmo tempo, como forma de garantia não apenas da sobrevivência da espécie humana, como também de qualidade de vida para as gerações atuais e futuras.

Nesse sentido, o Estado não apenas pode, como deve intervir no acesso privado aos meios naturais e na manutenção de sua posse, garantindo o respeito à função socioambiental. Destarte, como o que ocorre com o meio ambiente passa a ter carácter absoluto, o princípio da função socioambiental incorpora o interesse coletivo, incluindo ações negativas como a da limitação do uso em proveito da sustentabilidade (LEITE, 2004).

Nesse cenário, surge a noção de interesse comum da humanidade, firmado no direito internacional contemporâneo em vista de proteger os direitos humanos e o meio ambiente dos interesses específicos de indivíduos ou Estados. Trata-se de um produto da interdependência do mundo globalizado, essencial para se garantir o bem-estar de todos, pois reflete a emergência de tutelar fins pertinentes à totalidade do globo (AMARAL, 2011). Consagrado explicitamente em tratados internacionais nas últimas décadas, o interesse comum da humanidade impõe aos Estados a obrigação de, tal como acontece com os direitos e liberdades fundamentais, assegurar a fruição de meio ambiente saudável para as atuais e futuras gerações.

No âmbito nacional, em que pese os direitos socioambientais, ditos "novos direitos", como a proteção ao meio ambiente, à cultura, aos povos indígenas e quilombolas e à função socioambiental da propriedade, se encontrarem constitucionalmente consagrados, deve se buscar a plena efetivação desses direitos. Para tanto, eles devem ser interpretados de forma sistêmica e englobante, de forma inter e transdisciplinar (SANTILLI, 2006). Essa percepção visa assegurar uma existência digna, através da garantia de uma vida com qualidade. Não se trata de impedir o crescimento econômico, posto ser sabido que a atividade econômica, na 
maioria das vezes, representa alguma degradação ambiental. Trata-se, no entanto, de procurar minimizar seus efeitos colaterais das atividades desenvolvidas, lançando-se mão dos instrumentos existentes adequados para a menor degradação possível (FIORILLO, 2009).

\section{AgROECOLOGiA E SUSTENTABILIDADE: PARADIGMAS AO PRINCÍPIO DA PROTEÇÃo AMBIENTAL PÓS-MOdERNA PARA A CONEXÃo DO DIREITO AMBIENTAL E DO DIREITO AGRÁRIO}

A jurisdicionalização de preceitos ambientais na amplitude de sujeitos indeterminados, como busca de um desenvolvimento econômico capitalista, resguardado os direitos fundamentais e sociais. O (des)envolvimento da sociedade e do Estado para a construção igualitária de oportunidades, principalmente, no que tange os trabalhadores rurais. O manejo produtivo nesse viés, entrelaçado com a sustentabilidade, em confronto ao agronegócio e a produção extrativista de desiquilíbrio e desrespeito ambiental, social e de direitos fundamentais.

O meio ambiente além de fonte de exploração capitalista, e do manejo predatório para a produção agrícola. O meio ambiente como fonte vital e de (des)envolvimento individual de (re)construção de identidade de indivíduos, em conformidade com a pósmodernidade capitalista mas também, a transconstucionalidade de direitos fundamentais pelo resguardo ambiental.

De modo que, a agroecologia surge como um conjunto de procedimentos que visa a compreensão e integração dos recursos naturais como fomento à produção agrícola sustentável. Trata-se, aqui, além do modismo de economia produtiva que constantemente resolve problemas que as competentes pesquisas agrárias veem-se cerceadas pela alto custo tecnológico. Mas na ruptura da visão tradicional e costumeira, que constrói uma engrenagem social, a ser referendada pelas políticas públicas e estatais de fomento a produção sustentável. Portanto, a agroecologia tem uma visão integral e integradora de aspectos sociais, políticos, econômicos e Estatais no melhoramento técnico pautado pela sustentabilidade. Proporcionase assim, uma práxis social, intectual e política que pressiona ao Estado e as políticas econômicas no readequamento produtivo.

A agroecologia pela prática de manejo produtivo sustentável é na verdade uma forma de englobamento de setor em déficts de direitos fundamentais ao desenvolvimento capitalista. O capitalismo como asseveramos em momento oportuno neste trabalho, tem como principal característica a segregação, opressão e marginalização da sociedade. Nesse sentido, os 
indivíduos são expropriados da força de trabalho e depois do meio ambiente antes como condição vital, agora como condição econômica. São, portanto, constantemente olvidados pelo Estados e tem seus direitos fundamentais negligenciados.

Ao se pôr em prática um desenvolvimento sustentável, que procura o equilibro ambiental na mesma proporção de equiparação de oportunidades, encontra-se um desenvolvimento social de direitos fundamentais destes indivíduos, que outrora foram marginalizados pelo capital e o Estado moderno. Acredita-se, nesse sentido, que por meio da agroecologia e da sustentabilidade, a elevação de níveis de qualidade social em um Estado pautado pela desigualdade emergente da intensiva produção capitalista excludente.

Destarte, tem-se o novo paradigma sustentado neste trabalho. Almeida (2002) diz que a ideia é de integração e interação, indicando uma nova maneira de olhar e transformar o mundo, fundada no diálogo entre saberes e conhecimentos diversos. Desde modo, no mundo sustentável, uma atividade agrícola não pode ser pensada ou praticada em separado do meio ambiente, porque tudo está inter-relacionado, em permanente diálogo.

Esta nova maneira de pensar foi construída, em grande parte, a partir dos resultados da Rio-92, onde a noção de desenvolvimento sustentável se alastrou e se estruturou pelo mundo. No entanto, o que esta noção e os conceitos de sustentabilidade trazem como novo desafio são os caminhos da proteção pós-moderna ao princípio da função socioambiental. Ou seja, a proteção político-econômica pela via Estatal. Por meio da legislação e de políticas públicas e Estatais de incentivo dessa nova interação social no manejo produtivo.

A ressignificação de preceitos ambientais colocou em xeque o desenvolvimento meramente extrativista-econômico a partir das novas formas de preservação. Foi preciso neste ponto pensar que sustentabilidade é a desenvoltura de ser sustentável. A sustentabilidade de um modelo agrícola consiste na sua habilidade em manter o seu estado saudável condição desejável e/ou aceitável, necessário para a sobrevivência do sistema agricultável com alto nível de qualidade (KO, 2005).

A simples essência da palavra sustentabilidade já permite agregar múltiplos significados, tais como: manejo agroecológico; equidade de produção; manutenção dos ecossistemas; manutenção da resiliência natural e do homem; e redistribuição de poder (MCCOOL, 2001). Segundo Molina, “[...] a sustentabilidade não implica, sob qualquer circunstância, sustentar o status quo ou a ordem das coisas existentes" (MOLINA, 2001); reconhece a necessidade de mudança como força para manter a viabilidade tanto dos processos ecológicos como dos sociais e culturais. 
Essa conscientização nos dirigirá ao desenvolvimento sustentável, acentuado no Relatório Brundtland, elaborado pela Comissão Mundial do Meio Ambiente e Desenvolvimento (1988), como “[...] aquele que atende as necessidades do presente sem comprometer a possibilidade de as gerações futuras atenderem às suas próprias necessidades". Esse novo paradigma necessita ser acompanhado por uma modificação de valores, passando da expansão exploratória para a conservação, da quantidade para a qualidade, da denominação para a parceria.

A problemática ambiental deriva do desenvolvimento de contradições inseparáveis à lógica de operação do sistema capitalista. A sua emergência configura campos de disputas de interesses a partir dos quais se definem os moldes em que a questão ambiental tanto é compreendida como é equacionada. Desta maneira, esse campo tanto pode se formar em torno de espaços e elementos restritos ao âmbito local, ou ao nacional, como pode envolver elementos circunscritos na esfera mundial ou nas relações entre países ou regiões.

Vale frisar novamente, contudo, que a função socioambiental da propriedade está aliada ao desenvolvimento humano, e também para a garantia protecionista da vida em seu sentido mais amplo, ou seja, compreendendo como sujeitos de direitos os seres vivos como um todo. Deste modo, percebe-se a intrínseca relação do princípio ambiental do ambiente sadio, tratado como um direito fundamental ao ser humano, e ao princípio da função socioambiental da propriedade como garantia fundamental de desenvolvimento econômico por vias sustentáveis.

A preocupação com a sustentabilidade modificou a maneira de promover o desenvolvimento econômico. Trata-se, agora de um paradigma que chama a atenção para os limites ambientais do crescimento econômico continuo excludente e predatório. Sua intenção é, desde logo, evitar o esgotamento dos recursos não renováveis, substituir ou reciclar amplamente os recursos não renováveis, substituir e impedir a restrição radical do bem-estar social das gerações presentes e futuras.

Dessa maneira, passa-se por três estágios teóricos no que concerne a agroecologia e o desenvolvimento produtivo sustentável. Primeiro, pela prática da sociologia rural em um desenvolvimento comunitário, quando da prática produtiva comum aos indivíduos que sobrevivem ao capitalismo. Segundo, pela modernização agrária em um desenvolvimento integral. A modernização de técnicas para o aumento produtivo desvencilhado do desenvolvimento individual e social. A partir daqui, quando a desigualdade atinge níveis de marginalização insustentáveis e em desacordo a preceitos fundamentais e universais de vida, tem-se a tomada de consciência. Isso porque, os indivíduos passam a perceber a realidade 
como nefasta ao desenvolvimento societário, e enxergam a capacidade de organização individual e social de confronto as politicas econômicas estatais impostas. E, terceiro, a perspectiva da sustentabilidade institucional para a prática de desenvolvimento rural sustentável, portanto, a resposta ao que os indivíduos pleiteavam, ao menos no plano formal.

Ao institucionalizar a sustentabilidade tem-se um novo Estado pautada do resguardo ambiental, na produtividade rural aliada à agroecologia e de disseminação de oportunidades. Não somente de fomento econômico, mas de (des)envolvimento dos indivíduos, em sua cultura, família e de respeito integral à vida, independente de sua espécie e do tempo em que se encontra.

De maneira que a agroecologia como manejo produtivo sustentável implica além da institucionalização do Estado, a compreensão de ferramentas de produção num enfoque sistêmica de tecnologias orientadas pelo respeito ao meio ambiente e a orientação dos trabalhadores rurais para o desenvolvimento técnico adequado.

\section{CONCLUSÃO}

Diante dos pontos levantados é válido destacar que a preservação ambiental na pós modernidade e com a instauração capitalista assume múltiplas facetas: de ordem econômica, social, desenvolvimentista e ambiental. Portanto, a partir destas normas reconhece-se a função socioambiental da propriedade como fundamento para a intervenção estatal na liberdade e no direito de propriedade em prol de uma classe inestimável de sujeitos. Logo, o desenvolvimento do modo de produção capitalista fez com que a sociedade moderna adotasse um modelo econômico que possui como objetivo primeiro a geração de renda por meio da expropriação e exploração da força de trabalho e também, do próprio espaço natural e rural.

Diante da incontestável influência do modo de produção agrícola na disponibilidade e conservação dos recursos naturais, conclui-se pela impossibilidade de analisar os institutos agrários sem atentar aos conceitos provenientes do Direito Ambiental. Assim, a análise pormenorizada do princípio da preservação do ambiente é indispensável na construção dos estudos dos agraristas.

O Direito Ambiental e o Direito Agrário não são antagônicos. Ao contrário, tratamse de ramos que devem ser analisados em conjunto. As questões agrárias e ambientais necessitam estabelecer relação equilibrada e voltada ao desenvolvimento sustentável. A preservação dos recursos naturais não deve constituir entrave ao desenvolvimento. No entanto, 
não se pode justificar o uso indiscriminado de fertilizantes, agrotóxicos, sementes de alto rendimento, pelo aumento da produtividade, uma vez se sabe que estas práticas implicam o esgotamento do solo, erosão genética, desertificação, aumento da temperatura do planeta, e, evidentemente, queda de produção de alimentos.

De acordo com o princípio da preservação do ambiente, o desenvolvimento das atividades agrárias deve considerar o impacto causado à natureza, a fim de buscar soluções que menos agridam o ambiente, ao mesmo tempo em permitem o crescimento econômico e social dos produtores rurais. Deste modo, permite-se que o ser humano permaneça cultivando os alimentos indispensáveis à sua sobrevivência, e que as gerações futuras também o façam.

Entende-se que os prejuízos econômicos, sociais, ambientais e energéticos, causados pelo modelo da agricultura moderna ou convencional, atingiram patamares de insustentabilidade, buscam-se, então, estratégias sustentáveis, viáveis economicamente de desenvolvimento regional, fundamentadas nas potencialidades naturais de cada agroecossistema.

Diante disso, o crescimento ilimitado, seja uma condição de riqueza e prosperidade de igual oportunidade, balizado na concepção que o acesso à terra é mais que uma mercadoria à disposição do capital: é um meio de razão existencial de toda uma comunidade e, especialmente, de efetiva realização de soberania popular e sustentabilidade. Outrossim, é latente vincular a preservação ambiental como princípio do Direito Agrário a fim de buscar a diminuição de desigualdade socioeconômica, na pluralidade de sujeitos e interferências culturais, reconhecendo o outro com suas particularidades em um sistema de confronto ao capitalismo, havendo um equilíbrio entre anseios, sustentabilidade em seus pleitos para atuação jurídico-estatal.

Por tal razão, trouxe o trabalho o uso da agroecologia e da sustentabilidade como nova vertente hermenêutica que ultrapassa espaços segmentados, em prol de um real desenvolvimento dos indivíduos por meio da relação do homem ao meio ambiente. O uso da preservação ambiental aliada a hermenêutica da agroecologia e da sustentabilidade dá azo ao resultado que deve ser amparado pelo Direito Agrário: o uso do meio ambiente de maneira adequada, que mantenha sua biodiversidade e o meio ambiente equilibrado às futuras gerações aliado ao desenvolvimento e reconhecimento do homem ao meio ambiente que vai além das cifras impostas pelo capitalismo: uma relação vital que necessita de parâmetros que relacionam o Direito Agrário ao Direito Ambiental. 
O debate acerca da preservação do meio ambiente não constitui discurso passageiro.

E, por certo, este trabalho não esgota o assunto. Espera-se, todavia, provocar a reflexão dos agraristas há muito acostumados a tratar com desvelo o princípio da função social, chamandolhes a atenção para o princípio da preservação do ambiente.

\section{REFERÊNCIAS BIBLIOGRÁFICAS}

ALEXY, Robert. Teoria dos direitos fundamentais. 2. ed. São Paulo: Malheiros, 2011.

ALMEIDA, F., O bom negócio da sustentabilidade, Rio de Janeiro, Nova Fronteira, 2002.

ALTIERI, Miguel. Agroecologia: a dinâmica produtiva da agricultura sustentável. 5 ed., Porto Alegre: Editora UFRGS, 2004.

AMARAL, Alberto do Júnior. Comércio Internacional e a Proteção do Meio Ambiente. São Paulo: Atlas, 2011.

BARROSO, Luis Roberto. Curso de Direito Constitucional: os conceitos fundamentais e a construção do novo modelo. São Paulo: Saraiva, 2009.

BECK, Ulrich. La invencion de lo politico. Para una teoria de la modernizacios reflexiva. Trad. De Irene Merzari. Buenos Aires: Fondo de cultura econômica, 1999.

La sociedad del riesgo global. España: Siglo Veintiuno, 2002.

CARVALHO, Edson Ferreira de. Meio ambiente \& direitos humanos. Curitiba: Jurua Editora, 2008.

CONFERÊNCIA DAS NAÇÕES UNIDAS SOBRE MEIO AMBIENTE E DESENVOLVIMENTO. Convenção sobre Diversidade Biológica. Jun. 1992. Disponível em: <http://www.cdb.gov.br/CDB/cdb1>. Acesso em: 4 jul. 2010.

EHLERS, Eduardo. Agricultura sustentável: origens e perspectivas de um novo paradigma. 2 ed., Guaíba: Livraria e Editora Agropecuária, 1999.

FIORILlO, Celso Antônio Pacheco. Curso de direito ambiental brasileiro. 10 ed., São Paulo: Saraiva, 2009. 
GLIESSMAN, Stephen R. Agroecologia: processos ecológicos em agricultura sustentável. 3. ed. Porto Alegre: Editora UFRGS, 2005.

GIDDENS, Anthony. Capitalismo e moderna teoria social. $6^{\mathrm{a}}$ ed. Lisboa: Editorial Presença, 2005.

HESSE, Konrad. A força normativa da Constituição. Porto alegre: Sérgio Antonio Fabris Editor, 1991.

Ko, T.G. Development of a tourism sustainability assessment procedure: a conceptual approach, em: Tourism Management, n. 26, Rio de Janeiro, Elsevier, 2005, p. 431-445.

LEITE, José Rubens Morato; AYALA, Patryck de Araújo. Direito ambiental na sociedade de risco. 2. ed. rev. atual. e ampl. -. Rio de Janeiro: Forense Universitária, 2004.

LÖWY, Michael. Ecologia e Socialismo. São Paulo: Cortez, 2005.

MACHADO, Altair Toledo. et. al. A agrobiodiversidade com enfoque ecológico: implicações conceituais e jurídicas. Brasília: Embrapa Informação Tecnológica, 2008.

MARQUES, Benedito Ferreira. Direito Agrário Brasileiro. 6 ed., Goiânia: AB, 2005.

MCCOOL, S.F., Moisey, "What should tourism sustain? The disconnect with industry perceptions of useful indicators", em Journal of Travel Research, vol. 40, South Africa, Sage Publications, 2001, p. 124-131.

MILARÉ, Édis. Direito do ambiente: a gestão ambiental em foco. 6 ed., São Paulo: Editora Revista dos Tribunais, 2009.

MOLINA, E. S., Turismo e Ecologia, Bauru: EDUSC, 2001.

SANTILLI, Juliana. Os "novos" direitos socioambientais. Revista Direito e Justiça Reflexões sociojurídicas. Ano VI. N. 9, novembro, 2006

SHIVA, Vandana. Monoculturas da mente: perspectivas da biodiversidade e da biotecnologia. São Paulo: Gaia, 2003.

SOUZA, Washigton Peluso Albino. Comentários sobre direitos humanos e meio ambiente. In: BROWN WEISS, E. Et al (eds) Derechos humanos, desarollo sustentable y médio ambiente.

San

Jose:

IIDH-BID,

1995 
VEIGA, José Eli da. O desenvolvimento agrícola: uma visão histórica. São Paulo: Editora da Universidade de São Paulo, 1991.

VOGTMANN, Hartmut; WAGNER, Ralf. Agricultura ecológica: teoria e prática. Porto alegre: Editora Mercado Aberto, 1987.

WALTERS-BAYER, Ann. et. al. Agricultura para o futuro: uma introdução à agricultura sustentável e de baixo uso de insumos externos. 2 ed., Rio de Janeiro: AS-PTA; Leusden, Holanda: ILEIA, 1999.

UNESCO. Declaration on the Responsibilities of the Present Generations Towards Future Generations, 1997. 